\title{
How To Approach Internal Jugular Vein Aneurysm; A Rare Cause of Neck Mass
}

\author{
Ayşe Pelin Yiğider, Hasan Emre Koçak*, Hüseyin Avni Ulusoy and Mehmet Keskin \\ Bakirkoy Dr Sadi Konuk Research and Educational Hospital Otorhinolaryngology Clinic, Istanbul
}

Received: November 09, 2017; Published: November 13, 2017

*Corresponding author: Hasan Emre koçak, Bakirköy Dr. Sadi Konuk Eğitim ve Araștirma Hastanesi, Zuhuratbaba Mah. Tevfik Sağlam Cad No: 11, Bakirköy, Istanbul, Türkiye, Tel: 0905324630517; Email: drhekbb@gmail.com

\begin{abstract}
Venous aneurysms are rare entities especially while presenting neck mass. Internal Jugular vein anuerysms comprise a small part of all venous aneurysms.Natural history of the pathology depends on anatomic location. Surgical intervention is spared for symptomatic cases. We present a15 year old male who admitted to otorhinolaryngology clinic with expansile right lateral neck mass with out any pulsation. Physical examination revealed a normal morphology of cervial region. When the patient was asked to strain, an expansing soft painless mass appeared in the right supraclavicular region. The mass disappeared when the patient breathed normally. Lateral cervical cyst was suspected. Ultrasonography and magnetic resonance imaging with venography sequences were ordered. Dynamic measurements showed enlargement of right internal juguler vein with cross sectional diameter of $39 \mathrm{~mm}$ at proximal segment of the vein and reaching $59 \mathrm{~mm}$ vertically. Echocardiographic evaluation and thorax imaging showed no accompanying pathology. Doppler ultrasound showed well mucosal lining with substantial muscular layer without any thrombotic focus. Direction of flow was toward subclavian vein. Conservative approach was preffered for the case. Patient was followed up on for 1 year with no additonal symptom.
\end{abstract}

Keywords: Jugular vein; Aneurysm; Neck mass

\section{Introduction}

Internal jugular vein aneurysms and phlebectasias are the most common venous malformations in the head and neck region. Venous aneurysms are divided into two as primary and secondary aneurysms [1]. Secondary ones are mainly due to trauma, infection, inflammation, venous valve insufficiency and arteriovenous malformations. Primary ones are rare and focal saccular or fusiform dilatations of the veins. No incidence was reported in the literature but it is known to be equal between male and female. A venous aneurysm can yield symptoms at any age.

The pathology is rather benign, owing to the localization, they can lead serious complications such as thrombosis, pulmonary embolism, rupture and bleeding and pressure over neighbouring structures. A clear aetiology has not been yet established. Recent literature states that structural changes take place in the vessel wall due to increased matrix metalloproteinases [1]. The most common location for a venous aneurysm is lower extremities with popliteal vein is the leading one. Deeper locations are prone to be related with thrombosis and pulmonary embolism [2]. The symptomatology of the entity includes mass with pain and swelling. Surgical intervention for asymptomatic internal juguler vein aneuryms is generally due to cosmetic expectations opposing aneurysms of deep venous systems.

\section{Case Report}

15 year old male applied to otorhinolaryngology clinic with expansile right lateral neck mass with out any pulsation. Physical examination revealed a normal morphology of cervial region. When patient is asked to strain an expansing soft painless mass appeared in the right supraclavicular region (Figures 1 \& 2). As the Valsalva manuever was prolonged, the mass continued to swell. Nevertheless swelling disappeared when the patient breathed normally. Initially a lateral cervical cyst was suspected. Ultrasonography and magnetic resonance imaging with venography sequences were ordered. Static magnetic resonance imaging of neck did not reveal any pathology. Dynamic measurements showed enlargement of right internal juguler vein with cross sectional diameter of $39 \mathrm{~mm}$ at the proximal segment of the vein and reaching $59 \mathrm{~mm}$ vertically (Figures $2 \& 3$ ). Evaluation of thorax was achieved with computed tomography which also showed dilatation at the proximal part of the jugular vein (Figure 4). Echocardiographic evaluation and thorax imaging showed no accompanying pathology. Doppler ultrasound showed well mucosal lining with substantial muscular layer without any thrombotic focus (Figure 5). The lesion was reported as fusiform internal jugular vein aneurysm. Consultation with cardiovascular surgery was done and conservative approach was preffered. Patient 
was followed up on for 1 year with no additonal symptom (Figures 1-5).

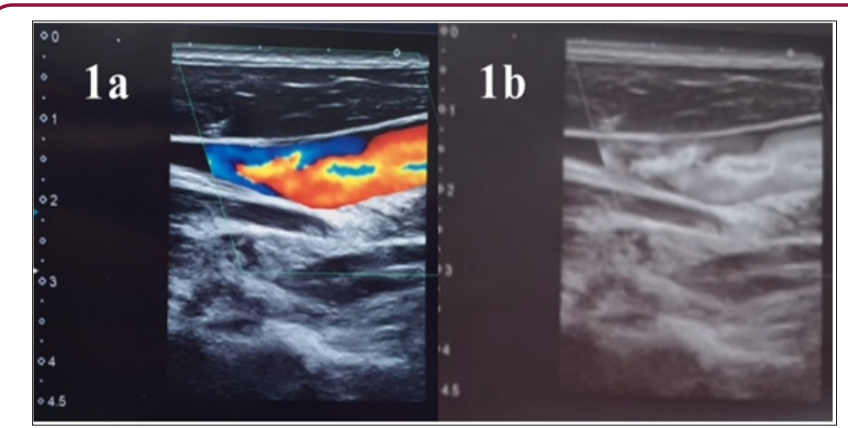

Figure $1 \mathrm{a} / \mathrm{b}$ : Doppler and classical ultrasound view of the lesion when it was not dilated.

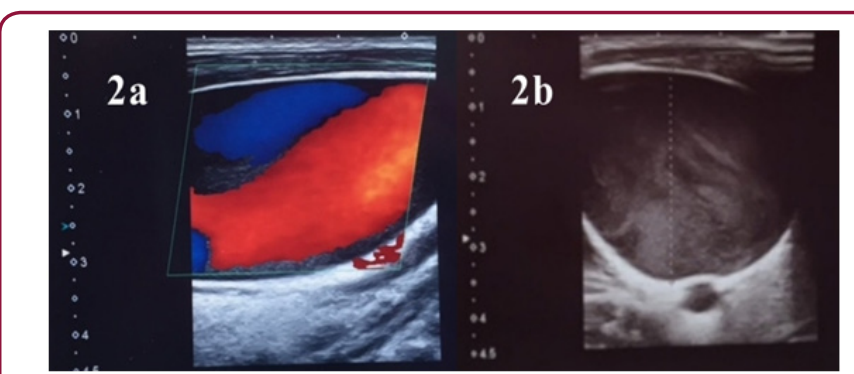

Figure $2 \mathrm{a} / \mathrm{b}$ : Doppler and classical ultrasound view of the lesion when the patient was asked to strain.

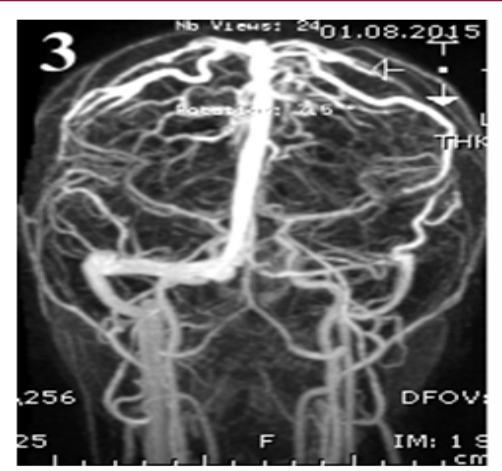

Figure 3: Magnetic resonance imaging of the patient with venography revealed dilated vein.

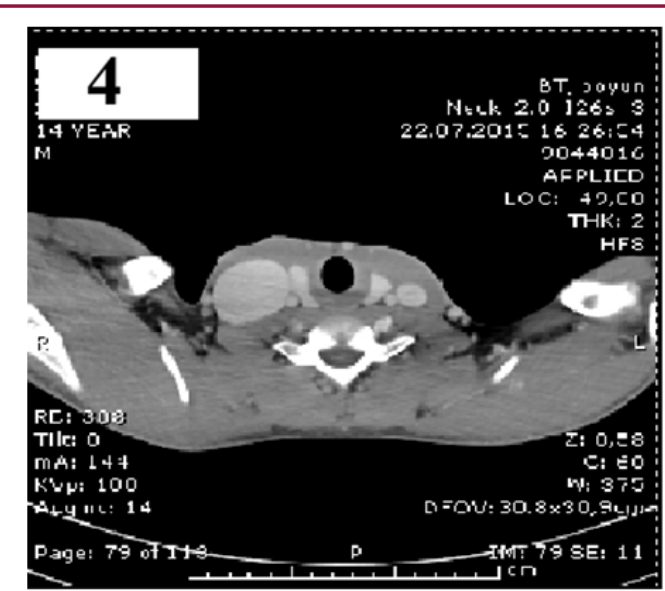

Figure 4: Evaluation of thorax was achieved with computed tomography which also showed dilatation at the proximal part of the jugular vein.

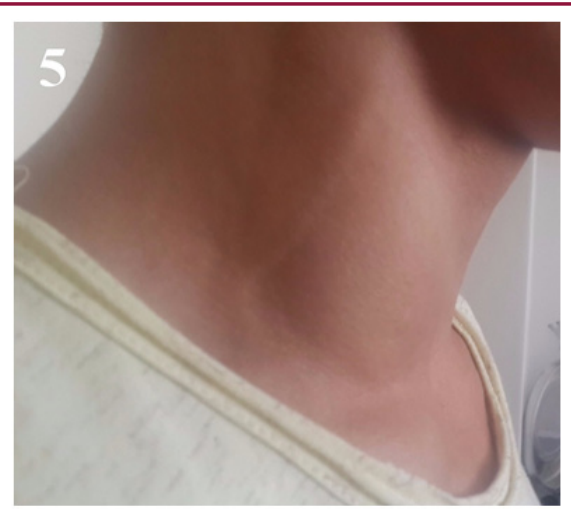

Figure 5: Patient's external appearance was shown in the photo.

\section{Discussion}

Patients who admit to otorhinolaryngology clinic with neck masses are applied a series of examinations. After physical examination ordering ulstrasonography generally gives enlightening information about the nature of the mass. Sometimes the mass can be dynamic such as laryngoceles, communicating cysts or blood vessels. In such cases patients should be asked to strain to swell the mass. Cervical adenitis, cystic hygroma, thyroglossal duct cysts, dermoid cysts, branchial cleft cysts and arterialvenous malformations are the most common pathologies which sould be kept in mind for differential diagnosis. Cervial masses could emerge due to a long list of diseases, however laryngoceles, superior mediastinal tumors or cysts and jugular vein aneurysms swell with the Valsalva maneuver [3]. If an asymptomatic jugular vein aneurysm starts causing symptoms such as pain, the clinician should suspect thrombosis.

Paleri et al. stated that up to $10 \%$ percent of the jugular aneurysms can be bilateral, therefore bilateral neck should be evaluated and followed up with doppler ultrasound [4]. According to the liaterature because of risk of thrombosis in IJV aneurysm is less than $1 \%$, in most of the cases conservative approach is preffered $[5,6]$. Because accompanying jugular vein thrombosis can complicate the case, due to increased risk for massive pulmonary embolism, some prophylactic measures, such as major venous vessel trunk isolation, can be taken.

Differentiating that whether the lesion is primary or secondary is the most important part because while the primary ones are more likely to be congential anomalies, a secondary anerysm is most likely due to highly mortal pathologies such as tumoral compression, thrombosis of vessel or other causes of vascular occlusion. According to the literature venous dilatation in pediatric age groups are generally fusiform in structure and symptomatic.

\section{Conclusion}

Primary venous aneurysms are rare and generally congenital. Careful follow up is an appropriate treatment. In case of complications such as thrombosis or rupture occur, interventions should be held. Nevertheless secondary ones should be intervened immediately due to the fact that they can be presenting symptoms of highly mortal conditions such as tumoral compression etc. 


\section{Acknowledgement}

The autors thank this patient for contribution to science.

\section{References}

1. Irwin C, Synn A, Kraiss L, Zhang Q, Griffen MM, et al. (2008) Metalloproteinase expression in venous aneurysms. J Vasc Surg 48(5): 1278-1285.

2. Gillespie DL, Villavicencio JL, Gallagher C, Chang A, Hamelink JK, et al. (1997) Presentation and management of venous aneurysms. J Vasc Surg 26(5): 845-852.

3. Kloppenburg GTL, Vries JPPM, Schuurman JP, Koelemij R, Jan Wille (2011) Current Perspectives on Management of Congenital Jugular Vein Aneurysms. Vasc Endovascular Surg 45(3): 237-240.
4. Paleri V, Gopalakrishnan S (2001) Jugular phlebectasia: theory of pathogenesis and review of literature. Int J Pediatr Otorhinolaryngol 57(2): 155-159.

5. Gallien S, Rollot F, Caron B, Moachon L, Bienvenu B, et al. (2006) Pulmonary embolism and deep jugular venous thrombosis resulting from compression by a lipoma. Dermatol Online J 12(2): 13.

6. Ascher E, Salles-Cunha S, Hingorani A (2005) Morbidity and mortality associated with internal jugular vein thromboses. Vasc Endovas-cular Surg 39(4): 335-339.

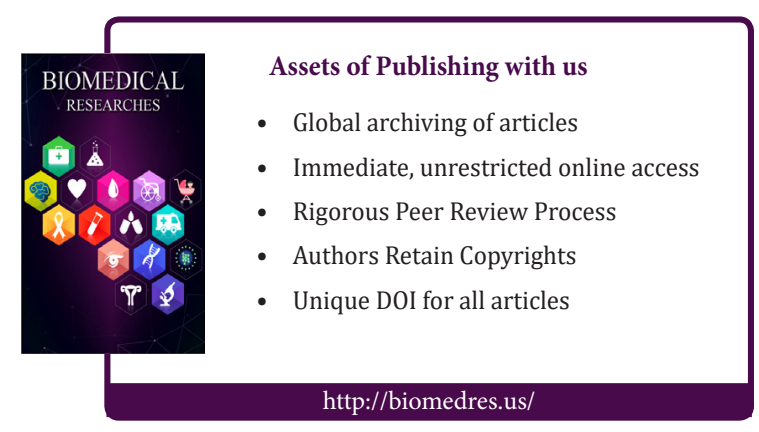

